\title{
Answering Korean Negative Questions by Elementary Students in Differing English Learning Contexts*
}

\author{
HyunSook $\mathrm{Ko}^{* *}$ \\ (The University of Ulsan)
}

\begin{abstract}
Ko, HyunSook. (2017). Answering Korean Negative Questions by Elementary Students in Differing English Learning Contexts. Language Research, 53.1, 105-134.
\end{abstract}

The study investigates whether different English learning contexts result in different grammar development in L1-specific structures in learners' mother tongue, Korean. Three groups of 8-to-10-year old students (i.e., EFL, immersion, and ESL learners) participated in the research. Participants completed a dialogue by choosing either Yes or No in Korean, and accuracy and reaction time were measured. The results showed little difference among the three groups in reaction time, but a significant difference between the EFL students and the ESL students in accuracy. The ESL students showed more limited knowledge with the peculiar but common structures in Korean. In the correlation analysis, length of residence in Korea had the strongest correlation, implying that the longer students lived in Korea, the better they correctly answered. The study enhances understanding of the complicated aspects of bilinguals' language development, particularly regarding L1 attrition or delayed development.1) In addition, it implies pedagogically that the mother tongue curriculum for bilingual learners could be well-served by more emphasis on enhancing learners' grammatical development, including language-specific structures.

Keywords: EFL, immersion, ESL, mother tongue development, reaction time

* This work was supported by the Research Fund of The University of Ulsan (2016R0003).

** Corresponding author: hyunsko@ulsan.ac.kr

1) The study discusses seemingly "delay" and "attrition" as a part of language development continuum, considering Cook (2003). 


\section{Introduction}

Bilingual2) education is emphasized all over the world. Particularly, in Korea, over $45 \%$ of elementary school students take additional English tutoring outside of their school (Lee, K. 2013; Statistics Korea 2014). However, some have expressed concern about the possibility of unbalanced development in L1 and L2 as well as severe financial burden (Cho, H. 1980; Kim, B. and Lyu 2014; Kwon, D. 1991; Lee, K. 2013). Diagnostic evaluations of learners' current development or achievement can make important contributions to making improved decisions for future education policy, including curriculum development. In this context, diagnostic evaluations of early English learners in Korea can be essential and practical action tools: they can provide not only firmer grounding for the current bilingual education policy but new directions for improvement. Considering the close relationship of mutual development between language and thought, early learning of English for children deserves sincere and delicate management.

However, there are few studies discussing how L1 (mother tongue) learners achieve, depending on differing learning contexts of L2, a language other than mother tongue. Recruitment of comparable groups of participants and design of a measurement able to be commonly administered among the groups (Han, Revesz, Park, E. H., Combs, and Kim, J. H. 2008) are challenging. The current study examines L1 developments by Korean elementary students learning English in different contexts. Specifically, the study focuses on Korean EFL learners' achievement in Korean in three contexts of second language acquisition as well as in language policy administration: leaning English as a second language (ESL), learning English as a foreign language at school in the program of only English (immersion), and learning English as a foreign language at school through two languages, Korean and English (EFL).

2) Bilinguals in the current study refer to L2 learners who have input sources other than L1 in their language use, regardless of their proficiency in the second or foreign language, following Ko, H. (2008). 


\section{Background}

\subsection{Development of Multicompetence}

The main frame of bilinguals' language system in this study is relevant to multicompetence in Cook (1991). The researcher used the term "multicompetence" when discussing L1 development in the context of second or foreign language acquisition, rather than assuming completely separate systems. In addition, Cook (2003) specified three possible models of relationships of languages on a continuum, as in Figure 1.

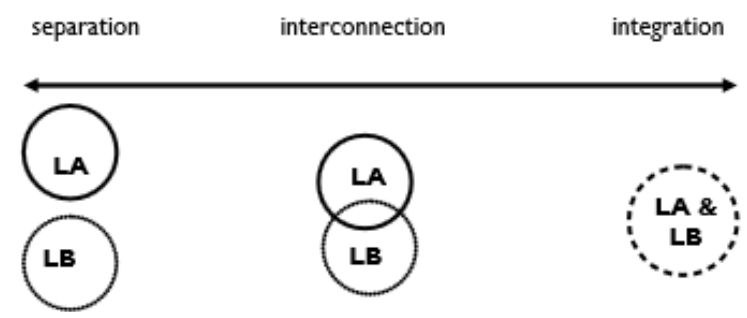

Figure 1. Possible Relationships in Multicompetence (Cook 2003: 9).

In the figure, LA and LB represent a mental system of each language, administering the use of each language. Interestingly, the relationship between LA and LB is represented as an "integration continuum," ranging from full separation of the language systems to interconnection and finally to integration as a single mental system. According to Cook (2002, 2003, 2008), "multicompetence" (meaning multilingual competence in the study) is not a fixed or a separate state of a limited linguistic competence, but a flexible or compound state involving knowledge of two or more languages: separation, interconnection, and integration. Depending on learners' pace of development, the different elements of multicompetence may transit toward different directions on the continuum; for example, multilingual users sometimes may reveal integration in the field of pronunciation and grammar, but separation or interconnection in the field of vocabulary or discourse.

In addition to such possibility of different development aspect across linguistic elements, Kecskes (2010a) empahsized that there are qualitative 
differences between monolinguals and multilinguals as well as quantitative. Moreover, he even asserted that both structure and usage are equally important in multilingual development. Structure develops as a result of usage and also serves as one of the underlying factors of usage. These characteristics will be considered in our discussion on the results of the study.

\subsection{L1 Development of Second or Foreign Language Learners}

Many recent studies adopt or support the model of multicompetence development involving interaction between or among languages rather than unidirectional model (Schjerve and Vetter 2012). For example, Tablebi (2013) examined reading by learners in three languages and concluded that improvements in the process of reading in one language resulted in improvements in another. Kecskes (1998) reported different subordinate clause frequencies in L1 writing of Hungarian 14 to 16 year-old students, depending on the their second language background, including the number of second language curriculum class hours. In addition, Liu and Carney (2012) investigated persuasive essays written in both English and Chinese by university and high school students in China learning English. They found that the university students' writing belonged to deductive organization of a discourse both in Chinese and English more than the high school students' writing. Thus, Liu and Carney (2012) concluded that the multicompetence of bilingual users at the conceptual level becomes stronger as their second or foreign language proficiency increases. This conclusion supports Kecskes and Papp (2003) and Lim, J. (2015).

In speaking, Pavlenko and Jarvis (2002) found that Russian university students learning English in the U. S. employed semantic aspects of English words in their story retelling in Russian. They also showed more frequent use of adjective-oriented structures, seemingly replacing the potential verb-oriented structures typical in Russian.

More interesting findings were reported in psycholinguistic research by Schoofs (2013). The researcher measured the speed to recognize words in L1 and participants' second language. The bilingual English/German 
participants who were over 40 showed faster access to their second language words than their L1 ones, after living in the second language culture for more than five years. This effect held at the level of individuals, but not across groups (i.e., two bilingual test and three monolingual control groups). In addition, the groups of participants with the youngest transition age of 13 to the second language culture showed the severest L1 attrition. This finding supports a 'critical period' for the loss of L1 competence of the previous studies (e.g., Pavlenko and Malt 2011; Schmid and Dusseldorp 2010; Ventureyra and Pallier 2004). Particularly, Schmid and Dusseldorp (2010: 129) suggested a time-span for the critical period 'roughly between the ages eight and 13 years.' According to them, attrition can be complete when it sets in before that time-span. When the onset of attrition is beyond the period, attrition typically remains limited. Integrating the findings of the previous and the researcher's own study, Schoofs (2013) concluded that entry age and the duration of stay in a second language environment have critical roles in L1 attrition and the researcher suggested the high probability that bilinguals have one merged language system, including lexicons.

Regarding the linguistic importance of contexts, of note is Kecskes (2010b), which showed that even situation-bound utterances with seemingly fixed conventionalized meaning successfully function with the help of both prior and the current contexts. Linguistic knowledge doesn't stay as a system out of the context, simply supervising language use with a fixed meaning in a specific form apart from the context. It always works together with the context of language use to construct or comprehend meaning at the time of use.

Integrating the previous studies above, we hold that bilinguals' multicompetence development has mutual impact on every language involved in an individual participant's learning, rather than limited impact in a unidirectional way of development. Among the various factors, entry age and stay of length in the target culture and interaction in authentic contexts seem to be major contributors to the development of multicompetence, particularly for early learners (meaning learners before puberty) and at the level of concept or word recognition in a linguistic system. 
Regarding Korean learners' multicompetence developments, particularly, four studies are of interest: Hwang, H. (2004), Lee, H.-J. (2000), Bae, J. (2006), Joh, J., et al. (2010), and Ko, H., et al. (2011). Hwang, H. (2004), and Lee, H.-J. (2000) reported no significant difference in vocabulary and story-telling in L1 between three-to-six-year old children with and those without learning English as a foreign language. Bae, J. (2006) found significantly higher achievement in L1 vocabulary and questionnaires by six-year old children in EFL than by those ESL, but not by seven-year old children.

On the other hand, Joh, J., et al. (2010) and Ko, H., et al. (2011) used more carefully specified second language learning contexts than other previous studies and produced directly comparable results, based on the data from the students at the ages of 8 to 10 who learned English in three different English learning contexts. Joh, J., et al. (2010) found different extents of impact across the linguistic areas in L1 across those three groups of students. The students who learned English either in the EFL or the immersion context showed comparable performance in their phonological development and reading comprehension in Korean. In contrast, those who learned English in the ESL context (meaning the context of learning English as a second language with usual opportunity to use the language outside a classroom) delivered significantly poorer performance in sentence repetition and reading comprehension tasks in Korean than the other two groups. Joh, J., et al. (2010) reported highest L1 vocabulary acquisition by students in the EFL context, the second by those in the immersion context, and the lowest by student $\mathrm{s}$ in the ESL context.

Ko, H., et al. (2011) also found significant differences between groups in a sentence composition task with Korean-specific double nominative structures, but not in a dialogue completion task with collocation expressions or a selecting task of correct grammatical forms which were relevant to commonly known interlanguage3) features in learning Korean (such as particles, verbs, and conjunctions). Thus, Ko, H., et al. (2011)

3) Our definition of "interlanguage" in this study follows Selinker (1972, 1992). It refers to 'a separate linguistic system based on the observable output which results from a learner's attempted production of a target language norm.' 
emphasized that Korean-specific structures function as linguistic features of importance to successfully probe significant difference in acquisition of Korean grammatical knowledge.

Integrating the previous research on Korean early learners, it seems reasonable to suppose that second and foreign language acquisition for Korean learners are involved in L1 development in some complicated ways. Depending on subfields of a linguistic system, the involvement resulted in conflicting (as in Choi, S. 1991 below vs. Joh, J., et al. 2010) or varied results (as in Joh, J., et al. 2010; Ko, H., et al. 2011). In particular, Korean-specific structures seem to work more successfully showing significant difference in bilinguals' language system, including different developments depending on L2 learning contexts.

Note here that there are several gaps in the previous research to reflect on before generalizing any of the conclusions. First, most of the previous studies on multicompetence development covered only a few languages, such as Hungarian, English, and German. As seen above, there is little research which includes Korean, if any. In order to obtain more convincing generalizations of the relationship of L1 development and second or foreign language acquisition, further research needs to expand the ranges of participants. To this end, the current study will investigate L1 development by Korean learners of English.

Another gap in the previous studies is that the previous research investigated learners' development in limited aspects of language development through product-oriented tasks such as word-picture matching, word identification, picture describing, story-retelling, reading/listening comprehension, answering to the questions given, discourse completion, and essay writing. Ongoing research needs to expand its field of exploration, in order to complete the whole picture of language development, including language processing itself. For example, research may develop an on-line grammatical task to examine some particular structures that are known to appear as errors frequently made by second or foreign language learners in their communication.

Finally, there has been relatively little research using language-specific structures in the field of bilinguals' acquisition, though they were some- 
times found to be quite successful in identifying critical characteristics of bilinguals' language system on development (Kang, S.-G. 2011; Ko, H. 2008, 2009). Examples of several language specific structures in Korean are double nominative structures (Ahn, S. 2006; Ko, H. 2009; Ko, H., et al. 2011; Lim, H. 2007; Li and Thompson 1976) and answer to negative questions (see below). Note that, as emphasized in Ko, H., et al. (2011), more sensitive measurements are needed particularly for bilingual grammar development in order to enhance accurate understanding of bilinguals' language system.

2.3. Bilinguals' Answering of Negative Questions in Korean and English

There are few previous studies examining bilinguals' answering negative questions. Most current research compared the error rate of monolinguals' responses to negative questions and discussed similarities and differences of linguistics system between monolinguals and bilinguals. One of the most integrative discussions is found in Akiyama (1992). Through critically overviewing previous studies dealing with English, French, Japanese, and Korean, he suggested a strong possibility that all children with different language backgrounds seemed to start answering negative questions using the English system. Supportive evidence was found in Choi, S. (1991). According to her, children, ranging from one-year-eight-month to three-year-four- month old, showed a similar pattern in answering questions regardless of their differing language backgrounds. Akiyama (1992) also asserted that English negative questions are affirmatively represented in language processing. More specifically, Ko, H. (2008) reported different reaction times to negation depending on specific grammatical structures in Korean adult bilinguals. They showed that affixal type of negation with 'an' in Korean does not, but that sentential type of negation with '-ci anh' does engage affirmative representation in its processing. The following are such examples: 
(1) In Korean

Affixal negative question

Pap an mek-ess-ni? (Did you have no meal?)

Sentential negative question

Onul cikakha-ci anh-ass-ci? (Aren't you late?)

Adopting Ko, H. (2008), when people speak or listen to a negative sentence as in 1(A) and 1(B), they do not construct the affirmative situation, you had a meal for 1(A), but they do, you were late for 1(B). One of the undeniable findings from these previous research on negation is that negation is a more complicated structure to acquire than affirmative statements and that the extent of complication becomes more severe especially for bilinguals whose L1 has different system of negation from English than otherwise.

For example, the following shows typological difference with potential processing burden between Korean and English negation.

(2) In Korean

A. Affirmative question

Ku saram ka-ss-ni? (Did he go?)

- Ani(yo) (No) [meaning he did not go.]

B. Negative question

Ku saram an ka-ss-ni? (Did he not go?)

- Ani(yo) (No) [meaning he went]

(3) In English

A. Affirmative question

Did he go?

- No [meaning he did not go.]

B. Negative question

Didn't he go?

- No [meaning he did not go.]

Note that ani(yo) in Korean means either affirmative or negative, depend- 
ing on the question type. When following the affirmative question, it means a negative preposition (e.g., he did not go in (2)A). When following the negative question, it means an affirmative preposition (e.g., he went in (2)B). Meanwhile, in English, no always means a negative preposition (e.g., he did not go in (3)A and (3)B). In other words, while the English system does not discriminate the stated question types, the Korean system distinguishes affirmative and negative questions in answering. Thus, it is reasonable to suppose that Korean bilinguals learning English may have more difficulty in processing negation than either monolinguals in affirmative statements or other bilinguals from language backgrounds without such typological difference from English. Supportive evidence of this reasoning was found in Choi, H. (2014). She reported that, in the question-and-answer session after listening to a short story, Korean bilinguals at the age of four to five year had most difficulties in two specific situations: when a negative question requires an affirmative form, ung/ney in answering to confirm the negative meaning; and when a negative question requires a negative form, ani(yo) in answering to disconfirm the negative statement. The following are such example.

(4) In Korean

A. Confirmation

Ku saram an ka-ss-ni? (Didn't he go?)

Ung/Ney (Yes) [meaning he did not go]

B. Disconfirmation

Ku saram an ka-ss-ni? (Didn't he go?)

Ani(yo) (No) [meaning he went]

Of note here is the mismatch in terms of negativity between the answering form itself and its message conveyed through the form. Ung and ney in (4)A have affirmative forms, but they present negative situations, he did not go. In contrast, ani(yo) in (4)B has a negative form, but it presents affirmative situation, he went. These conflicting relationships in negativity between the form and the situation it referred to seem to add psychological burden in information processing, particularly for Korean bilinguals learn- 
ing English. Actually, speech errors by adult Korean learners like 'No, he went.' in English have been one of the commonly well-known phenomena since Kim, S.-H. (1962) reported. In addition, according to Choi, H. (2014), Korean bilingual children showed significantly higher speech error rates in Korean than Korean monolinguals. They also showed significantly higher speech error rates in Korean than in English. As regards question types, they made significantly more speech errors in answering negative questions than affirmative ones. Through the analyses of interaction effects between question types, including truth-false verification, Choi, H. (2014) found the greatest errors in false negative questions, true negative questions, and false affirmative questions by Korean bilinguals; and true affirmative questions, false affirmative questions, true negative questions, and true affirmative questions by Korean monolinguals. Interestingly, in the interaction analyses by language and question types for Korean bilinguals, the research found the greatest error rate in false negative questions, true negative questions, false affirmative questions, and true affirmative questions both in English and Korean on the whole.4) Thus, Choi, H. (2014) concluded that bilingual children have two separate processing systems for yes-no truth-functional questions, and suggested a model that the two processing systems function in a different way from either English or Korean monolinguals' systems.

Integrating the previous studies, answering to negative questions in Korean seems to be a successful candidate to examine the extent of L1 development or attrition: due to typological differences between Korean and English and psychological burden in processing with the two contradictory yes-no answering systems. Thus, the current study designed an online experiment analyzing reaction time with subjects in differing contexts. The analyses of reaction time as well as accuracy of answering to negative questions in Korean will provide more informative discussion on the relationship of Korean bilinguals' L1development with English acquisition as a second and foreign language.

4) Specifically, in the question-and-answer session in English, the bilinguals showed a similar error rate between the true negative questions and the false affirmative questions (Choi, H. 2014: 279). 
In the selection of participants' age, the study considered the issues around what is called 'critical period' in the field of second language acquisition, which asserted that learners usually seemed to master their languages around six to 10 (Jasińska and Petitto 2017). Keeping in mind the discussions on the issue, the study selected 8-to-10-year old children. One of the two main reasons of such determination is that children of that age were successfully recruited across three different English learning contexts to compare (i.e., the EFL, the immersion, and the ESL contexts) at the time of research. The other reason is that they were expected to have little difficulty understanding the reading-and-typing task with negative questions and producing comparable answers in Korean. In Korea at the time of research, 8-to-10-year old children at elementary school had learned and practiced English questions for least two years. And the students in the immersion program and the ESL context certainly acquired communication skills using negative questions, considering their curriculum of English and daily lives. If participants were much older than 8-to-10-year old children, the risk of missing potentially significant differences across the learning contexts increases, because the students either master the answering systems in Korean or, otherwise suffer attrition of the system in their language development progress.

\section{Research Questions}

The current research proposes to investigate the following two questions:

(1) Do Korean bilingual children who are learning English in different learning contexts show differing grammatical accuracy in response to negative questions in Korean?

(2) Do Korean bilingual children who are learning English in different learning contexts show differing reaction time in response to negative questions in Korean? 
Task performance by students in these different learning contexts is compared in two aspects: the (non)existence of knowledge to choose correct grammatical forms and complete sentences in Korean, and the (dis)similarity of the process to complete the sentences using the target forms. The former was measured in terms of performance accuracy by students where they were asked to complete a dialogue with either appropriate affirmative or negative forms (i.e., ung/ney or ani(yo)). The latter is measured in terms of amount of time (i.e., reaction time) to spend completing the sentences.

\section{Research Method}

\subsection{Subjects}

Through face-to-face or paper introduction in 2008 and 2009, the researcher successfully recruited three groups of 8-to-10-year old: 1) 26 Korean EFL students studying at a public elementary school (henceforth, EFL students) in a small city around Seoul, Korea, 2) 21 Korean students attending an international school in Seoul (henceforth, immersion students), where English is taught entirely through English and used at home as well, 3) 19 Korean ESL students at a public elementary school in Austin, Texas, in the U.S. (henceforth, ESL students).5) The EFL students didn't have experience living in English speaking countries, but the learners in the other two groups had more than one year of residence in the $\mathrm{U}$. S. or Canada. These differences in history of residence imply that the students in each group have been exposed to different English curricula.

The following is a summary of their learning backgrounds, obtained through interview sessions after the tasks.

5) The subjects of the current study also participated in Joh, J., et al. (2010), Ko, H., et al. (2011). 
Table 1. Background of Subject Groups

\begin{tabular}{c|c|c|c|c|c}
\hline $\begin{array}{c}\text { Group: } \\
\text { English } \\
\text { Learning }\end{array}$ & $\begin{array}{c}\text { Number of } \\
\text { Participants }\end{array}$ & $\begin{array}{c}\text { Average Age } \\
(\text { months) }\end{array}$ & $\begin{array}{c}\text { Average } \\
\text { Length of } \\
\text { Residence in } \\
\text { Korea } \\
\text { (months) }\end{array}$ & $\begin{array}{c}\text { Average } \\
\text { Initial Age of } \\
\text { Exposure to } \\
\text { English } \\
\text { (months) }\end{array}$ & $\begin{array}{c}\text { Average } \\
\text { Length of } \\
\text { Learning } \\
\text { English } \\
\text { (months) }\end{array}$ \\
\hline \hline EFL & 26 & 112 & 113 & 93 & 26 \\
\hline Immersion & 21 & 118 & 72 & 49 & 69 \\
\hline ESL & 19 & 106 & 21 & 23 & 83 \\
\hline
\end{tabular}

The EFL students have taken two 45-minute English classes per week, which mainly teaches daily-used words and simple sentences in spoken form under a nationally standardized curriculum starting at the third grade of public elementary schools in Korea. Most of them were first exposed to English learning or English culture after 93 months (, corresponding with the grade two or three of elementary school, almost after the age of eight) and have less than a 26-month history of English learning. Meanwhile, the students in the immersion context have started to learn English around their 49th month (the age of four) and have been learning English for almost 70 months on average. Finally, the ESL students have started to learn English around their 23rd month (before the age of two) and have been learning for around 83 months on average.

\subsection{Research Procedures}

Keeping in mind the children's reasonable capacity for concentration, the researchers used the limited time and testing items.7) The research was comprised of response completion items (Appendix) to 18 questions given in Korean: three practice items with the affirmative forms of yes-no questions, five target items with the negative forms of yes-no questions, and ten fake items with the positive forms of yes-no questions in order to prevent potential bias. The fake items are similar to the target items in terms of vocabulary difficulty and the number of words, but different

6) Rounded.

7) For more details, refer to Doherty-Sneddon, Bruce, Bonner, Longbotham, and Doyle (2002). 
from the target items only in that they don't have negative forms.

Through oral and paper introductions provided by the researcher, a practice session with three items tried by every subject and the subsequent question-and-answer session, the subject had opportunities to fully understand the task structure. Each question is supposed to be understood independent from each other and that choices should be marked according to the system on the computer screen. The participants were asked to select a correct grammatical form of the two choices given, ung/ney and ani(yo). The test examines whether or not a participant has a grammatical knowledge of answering negative questions, which are known as commonly used and, at the same time, requiring determination by the Korean-specific language system. To make sure that the testing items were within the knowledge of those who acquire Korean through normal language use in Korea, all of the target words and expressions in both tests of lexicon and grammar were selected among the ones introduced in the textbooks of four language skills in Korean for second or third grade elementary school students in Korea by Kyoyukkwahakkiswulbwu (Ministry of Education, Science, and Technology 2000a, 2000b, 2001a, 2001b, 2001c, 2001d, 2001e). Before they started the task, participants were informed orally and also in a written text that there would be a time limit of 10 minutes for each test and that they could ask for help of the researcher at any time, including for clarification of the question. The instructions were given in Korean for EFL students and in English for the students in the immersion and the ESL contexts. The task required them to read a pair of a question and an answer containing a blank, which has to be filled with appropriate response of either ung/ney or ani(yo).

(5) below shows a translated version of an example of testing items presented on the computer screen, plus notes in the blanks to help readers' comprehension. 
(5) In Korean

Pap an mek-ess-ni? (Didn't you have a meal?) , an mek-ess-e. , I didn't) [meaning I didn't have a meal.]

Through the practice session, they were completed the response by pressing either the key of 1 for ung/ney by left hand; or the key, 0 for ani(yo/ya). For the participants' convenience, the key of 1 was marked with a sticker, ung on and the key of 0 with ani(ya).

Using the software, E-prime 2.0, the researcher recorded each participant's choice of the two keys and the reaction time spent from the presentation of a pair of a question and an answer with a blank until they press the answer key. After the test sessions completed, there was an interview for background information with each participant with no time limit. On average about eight minutes were taken for each task, including the practice session, and five minutes for each interview per participant.

\section{Results}

First, when using SPSS 17.0, an MANOVA test regarding background factors across three groups of participants exactly showed the same results as in Joh, J., et al. (2010) and Ko, H., et al. (2011), since the current study shared participants with the two studies. The result showed that all of the mean comparisons between participant groups were found significantly different in terms of learning background. As seen in Table 2 , the three groups were significantly different in length of residence in Korea, initial age of exposure to English, and length of learning English before the experiment date. 
Table 2. MANOVA Test Results of Background Factors of Participants

\begin{tabular}{c|c|c|c}
\hline & $\mathrm{F}(d f)^{8)}$ & $p$ & Effect Size \\
\hline \hline Length of Residence in Korea & $\mathrm{F}(2,57)=71.361$ & $p^{\star * *}<0.001$ & 0.830 \\
\hline Initial age of Exposure to English & $\mathrm{F}(2,57)=53.363$ & $p^{\star * *}<0.001$ & 0.791 \\
\hline Length of Learning English & $\mathrm{F}(2,57)=35.613$ & $p^{\star * *}<0.001$ & 0.710 \\
\hline
\end{tabular}

The results of the post hoc Bonferroni test of pair-wise comparison of the three factors among groups confirmed at the level of $a=0.001$ (two-tailed) the following three facts were statistically significant: The EFL group had resided longest in Korea, followed by the immersion and then the ESL group. The ESL group had been first exposed to English at the earliest age, next the immersion, and then the EFL. Finally, the length of learning English was shortest in the EFL group, followed by the immersion and then the ESL groups. These results imply that our research has selected appropriate learning contexts with distinguishable characteristics for group comparisons. ${ }^{9)}$

For this analysis, correct responses for the five negative questions were counted to represent individual students' grammatical competence in the task mentioned above. On the other hand, each reaction time to the five negative questions were recorded and divided by the average reaction time for three fake items. Thereby, the reaction times of each participant were standardized to compare across three groups to examine the extent of (dis)similarity in processing. For example, when a participant responded 4,000 milliseconds for one negative question and his average reaction time for three fake items was 6,000 milliseconds, his standardized reaction time for the negative question is $\left.0.67(4,000 / 6,000) .{ }^{10}\right)$ The Cronbach's alpha reliability coefficient was 0.646 for the five negative forms of questions.11) The following are descriptive statistics of the test.

8) The minor differences of $\mathrm{df}$ in the table across factors are due to missing data (including responses such as "I don't remember how long..." or "I am not sure when ...").

9) In the correlation analyses, the Pearson correlation was found highest between the length of time living in Korea and the participant groupings (Pearson Correlation $\left.=0.844, p^{* *}<0.01\right)$.

10) Refer to Ko, H. (2008).

11) The coefficient does not seem enough to assert that the measurement is reliable across the items. Such weakness might be originated for the limited number of target 
Table 3. Descriptive Statistics of the Correct Responses to Five Negative Questions

\begin{tabular}{c|c|c|c}
\hline Group & $\begin{array}{c}\text { Average Number of } \\
\text { Correct Responses }\end{array}$ & Standard Deviation & $\begin{array}{c}\text { Number of } \\
\text { Participants }\end{array}$ \\
\hline \hline EFL & 4.346 & 0.689 & 26 \\
\hline Immersion & 4.238 & 1.044 & 21 \\
\hline ESL & 3.158 & 1.259 & 19 \\
\hline
\end{tabular}

Note. Scores in the table represents the raw numbers of correct answers to five negative questions.

Table 4 shows the results of the MANOVA test by SPSS 17.0.

Table 4. Results of MANOVA Test with Responses to Five Negative Questions

\begin{tabular}{c|c|c|c}
\hline & $\mathrm{F}(d f)^{12)}$ & $p$ & Effect Size \\
\hline \hline Accuracy & $\mathrm{F}(2,63)=8.970$ & $p^{* \star *}<0.001$ & 0.276 \\
\hline Reaction Time & $\mathrm{F}(2,63)=1.084$ & $p=0.344$ & 0.033 \\
\hline
\end{tabular}

As seen above, the results showed that there is significant difference in the number of correct responses, that is accuracy, to negative questions $\left(\mathrm{F}(2,63)=8.970, p^{* * *}<0.001\right.$, effect size: 0.276 , observed power: 0.776$)$, but not in reaction time across the three groups of students. In the post hoc Bonferroni test of pair-wise comparison of response accuracy among groups, it was confirmed significant at the level of $a=0.05$ (two-tailed) that the EFL students outperformed the ESL students $\left(p^{*}=0.016\right.$, effect size: 1.173$)$ in the test with negative questions in Korean. In addition, the immersion students outperformed the ESL students $\left(p^{*}=0.044\right.$, effect size: 0.934$)$. However, no significant difference was found in other comparisons of groups.

These results are very interesting in that the study has provided supportive evidence of children's better performance in their L1 in terms of accuracy (i.e., the product of processing), not in processing itself. This

questions. Further research may improve the test reliability, in part through increasing testing items as well as managing the fatigues of the children.

12) The minor differences of $\mathrm{df}$ in the table across factors are due to missing data. 
implies that the ESL students' L1 knowledge and use of Korean-specific structures have been developmentally delayed, compared to those in the other groups in the study. At the same time, their amount of time investment to comprehend negative questions and determine the responding forms does not have a distinguishable difference from those in the other groups. One possible explanation of these two facts would be that the ESL students did not recognize the incorrect functioning of their intuitions for the testing items and that they kept a consistent pace in answering across affirmative and negative questions.

The additional MANOVA tests of responses to positive questions showed the results support for this. The following are descriptive statistics of the test.

Table 5. Descriptive Statistics of the Reaction Time to Seven Positive Questions

\begin{tabular}{c|c|c|c}
\hline Group & $\begin{array}{c}\text { Average Reaction } \\
\text { Time (standardized, } \\
\text { unitless) }\end{array}$ & $\begin{array}{c}\text { Standard } \\
\text { Deviation }\end{array}$ & $\begin{array}{c}\text { Number of } \\
\text { Participants }\end{array}$ \\
\hline \hline EFL & 1.038 & 0.304 & 26 \\
\hline Immersion & 0.762 & 0.276 & 21 \\
\hline ESL & 0.981 & 0.285 & 19 \\
\hline
\end{tabular}

Note. Scores in the table represents the standardized reaction time to seven positive questions that are divided by an individual subject's average reaction time and averaged for a group mean.

Table 6 is the summary of the MANOVA test results:

Table 6. Results of MANOVA Test with Responses to Seven Positive Questions ${ }^{13)}$

\begin{tabular}{c|c|c|c}
\hline & $\mathrm{F}(d f)^{14)}$ & $p$ & Effect Size \\
\hline \hline Accuracy & $\mathrm{F}(2,63)=0.737$ & $p=0.483$ & 0.023 \\
\hline Reaction Time & $\mathrm{F}(2,63)=5.605$ & $p^{* *}=0.006$ & 0.173 \\
\hline
\end{tabular}

13) Among the ten positive questions, the first three were used to calculate individual subject's average reaction time and only the remaining seven were included for the additional analyses for positive questions.

14) The minor differences of $d f$ in the table across factors are due to missing data. 
As seen above, the results showed that there is significant difference in reaction time to positive questions $\left(\mathrm{F}(2,63)=5.605, p^{* *}=0.006\right.$, effect size: 0.173 , observed power: 0.842 ), but not in in the number of correct responses, that is accuracy, to positive questions across the three groups of students. These findings suggest that the three groups of participants show similar achievements with each other in correctly answering positive forms of questions.

In the post hoc Bonferroni test of pair-wise comparison of reaction time among groups, it was confirmed significant at the level of $a=0.01$ (two-tailed) only that the EFL students took longer than the immersion students ( $p^{* *}=0.006$, effect size: 0.950$)$ in the test with positive questions in Korean. No significant difference was found in other comparisons of groups. Note that the ESL students took similar reaction time with the EFL students whether the question was positive or negative, but that they showed significantly lower accuracy only for negative forms of the questions. In addition, the immersion students answer significantly faster than the EFL students for the positive question form.

Integrating the results above, there is a strong possibility that the differing learning contexts of English either accelerate or delay the development of the learners' L1, Korean, exclusively between accuracy and reaction time, depending on the forms of questions: for positive forms, immersion students were the fastest in answering and the ESL was comparable to the EFL in terms of reaction time. Meanwhile, for negative forms of questions, the EFL students showed the highest accuracy and outperformed the ESL students. One possible interpretation is that accurate comprehension or full processing of negative sentences might be achieved by EFL students, while incomplete comprehension by the immersion and the least comprehension by the ESL even after using quite amount of reaction time. To confirm this possibility, more specified research with balanced number of positive and negative questions is necessary.

Such results might raise a question, what specific factors among the ones characterizing English learning contexts closely relate to differing accuracy in completing answers to negative questions in Korean? To answer this question, the study performed correlation analyses of three factors 
(background information in the interview about learning context or history) with the scores in the negative question test: the lengths of studying English and living in Korea, and the initial time of studying English, which were obtained through interview sessions. The results are as follows in Table 7:

Table 7. Correlation between Contextual Factors and the Test Scores for Five Negative Questions

\begin{tabular}{c|c|c}
\hline Factors from Learning Context & $\begin{array}{c}\text { Pearson Correlation } \\
\text { Coefficient }\end{array}$ & Significance \\
\hline \hline Length of Learning English (months) & -0.193 & $p=0.130$ \\
\hline Length of Residence in Korea (months) & 0.307 & $p^{*}=0.013$ \\
\hline Initial age of Exposure to English (months) & 0.269 & $p=0.330$ \\
\hline
\end{tabular}

These results imply that among the context factors, length of residence in Korea is the only good predictor about how well a participant would perform in the completion test of answers to negative questions (Pearson Correlation Coefficient: $\left.0.307, p^{*}<0.5\right)$. These finding support Ko, H., et al. (2011) and make it more generalizable.

At the same time, the results above provide a supportive evidence for Kecskes (2010a), who asserted that both structure and usage are equally important in multilingual development. The ESL students' relative poor performance and the EFL students' best performance among the three groups in the test seem to originate from lack of usage, reflecting length of residence and amount of exposure to the involved two languages. Kecskes' (2010a) assertion was supported by the results of the study that structure develops as a result of usage.

The findings above suggest that the social learning context of language learning works bi-directionally between the mother tongue and second or foreign language. This is in contrast to the heretofore emphasized unidirectional effect by mother tongue on a second or foreign language. The findings should draw language policy-makers' attention to the necessity that apart from emphasis of efficient teaching of English at elementary schools employing an ESL context (including immersion) in Korea, the 
school curriculum should also consider how to compensate for possible weaknesses in the development of Korean. For example, Joh, J., et al. (2010) showed that lexical development in Korean was significantly delayed by the second or third graders who are learning English in the immersion and ESL context. Moreover, the current study specified that such differences in the development of Korean language have significant correlation with length of residence. More research (including with older participants) would help to decide whether or at which specific age English learners in which type of learning contexts need intensive pedagogical intervention.

\section{Discussion and Conclusion}

The current study contributes empirical findings on bi-directional development of grammatical structure between L1 and second or foreign language both in terms of accuracy and reaction time. Based on these results, the first research question above has been answered in the partially positive: Korean bilingual children who are learning English in the EFL and the immersion contexts show similar accuracy with each other to complete the answer to negative questions in the test, but different performance from those in the ESL contexts. The ESL students show a significant delay in grammatical development in answering negative questions in Korean. Regarding the second research question, the research answered in the negative. Korean bilingual children show similar performance in answering negative questions in terms of reaction time regardless of their different English learning contexts.

In the field of second language acquisition, the findings of the current study added more evidence for the bi-directional development of language systems mentioned in the previous studies (Jarvis 2003; Kecskes 1998; Liu and Carney 2012; Pavlenko and Jarvis 2002; Pavlenko and Malt 2011; Schjerve and Vetter 2012; Schmid and Dusseldorp 2010; Schoofs 2013; Tablebi 2013; Ventureyra and Pallier 2004) and help its theory take more generalizable status. Most of all, the different achievements 
in Korean across English learning contexts by 8-to-10-year old students should be seriously taken as a evidence of a necessity for research that seeks for good balancing between L1 and second or foreign language in terms of exposure time and learning contexts. As Schmid and Dusseldorp (2010) predicted, the ESL children at the age of eight to 10 showed a poorer development in L1 in the current study. This finding suggests that pedagogical interventions may start with English learners at around eight to 10 year old to help them be good balanced bilinguals. When it is not sure whether the bilingual program well-balanced or not, it would also be a responsible attitude to make a consistent effort to regularly check L1 development or attrition, and provide compensatory lessons to help successful achievement at least until puberty, which is commonly assumed as the end of the critical period in language development.

One more fact to note in the study is the significant correlation with the scores between the lexical test by Joh, J., et al. (2010) with answers to negative questions in the current study. The Pearson Correlation between the two tests were $0.418, p^{* * *}<0.001$. This result implies that a participant with a better score in the lexical test also performed better in answering negative questions.

Another significant correlation was found with the scores between the sentence completion test with double nominative structures by Ko, H., et al. (2011) and that with answers to negative questions in the current study. The Pearson Correlation between the two tests was 0.333, $p^{* *}=0.006$. This result implies that a participant with a better score in the sentence writing test with the double nominative structures also performed better in answering negative questions. Note here that both of the tests measure the language performance or skills in Korean-specific structures. Thus the finding suggests that language-specific grammar is vulnerable to the influence of second language acquisition, which may result in either delay in L1 development or observed L1 attrition.

Regarding bilinguals' language system, the results imply that lexical and grammatical development in L1 and second or foreign language keep along with each other in some aspects, but not in a linear way. As seen above, they seem to progress in a quite complicated way with respect 
to accuracy and reaction time as well as the length of residence in L1 culture. These findings call more careful attention to understanding the model of bilinguals' language system suggested by Cook (2003) in a multidimensional way rather than in a two-dimensional one.

In summary, the study found that the ESL students who were characterized by shorter residence in Korea and earlier exposure to English were not as competent as EFL students in terms of lexical knowledge and grammatical knowledge of Korean-specific structures, but similar in their performance across the different learning contexts in the grammar test of basics for elementary schoolers and learners of Korean as a foreign language. Considering the high correlation of the scores between the lexical test and the sentence writing test found in the study, success in lexical development would determine corresponding development in Korean-specific grammar. This interpretation supports the view of Ko, H., et al. (2011): Development of a mother tongue is progressing at a different pace or delayed in Korean learners who are learning English across three critical contexts of bilingual education; at least Korean-specific structures need active instructional intervention to compensate for potential lack of knowledge and skills in use of Korean sentences by elementary school children who are learning English in the ESL or the immersion context.

Related to pedagogic practice for bilinguals, the findings imply that pedagogical priority should be given through active intervention by instructors and curriculum development on compensating or emphasizing in advance of language attrition the grammatical structure with typological characteristics (such as double nominative and answers to negative forms of questions) in L1. Otherwise, delayed development or attrition in L1 seems likely to be inevitable or remain for a while at the age of 8-to-10, as seen in the current study.

In spite of those interesting findings, the current study, however, has a limit that it did not specify one specific factor and control other factors than the specific factor enough to produce any clear cause and effect relationship between the characteristics of learning contexts and L1 attrition or delayed development. Note that the current study found the highest correlation between length of residence in Korea and lexical/grammatical 
development in L1. This has, thus, remained as another of the promising topics for further research that pursues more generalizable and reliable conclusions on bilinguals' language development. Other limitations include the small size of participants, limited number of items and lack of consideration of a longitudinal aspect in bilinguals' language development. Further research, for example, would compare bilinguals' performance with balanced number of positive and negative forms of questions and provide more informative findings on L1 and second language development. In addition, further longitudinal research may pursue the question of whether or not bilinguals with heavy English backgrounds eventually catch up to their peers in EFL context.

\section{References}

Ahn, Sungho. (2006). The grammar of verb be in early Korean FL interlanguages. Studies in Generative Grammar 16, 769-782.

Akiyama, Michael. M. (1992). Cross-linguistic contrast of verification and answering among children. Journal of Psycholinguistic Research 21.2, 67-85.

Ko, HyunSook. (2008). Different sentence processing by native English speakers and Korean bilinguals, English Teaching 63.1, 71-99.

Ko, HyunSook. (2009). Acquisition of a subject in English sentences by Korean learners. Korean Journal of Applied Linguistics 25.1, 199-226.

Ko, HyunSook, Lim, Injae, Joh, Jeongsoon, and Lee, Shinsook. (2011). Grammatical development of Korean by elementary school students in differing English learning contexts. English Teaching 66.4, 165-189.

Bae, Jungok. (2006). Reading ability in Korean as a first and second language achieved during the early phase of Korean/English immersion education in America. Language Research 42.1, 161-185.

Cho, Hongseop. (1980). Yengecokikyoynkey kwanhaye: Simlicek yoinkwa mwuncecemul cungsimulo (On early learning of English: Focusing on psychological factors and problems). The Modern English Society of Korea 16.1, 187-204.

Choi, Hansook. (2014). The answering system to yes-no truth-functional questions in Korean-English bilingual children. Journal of Psycholinguist Research 43, 267-287.

Choi, Soonja. (1991). Children's answers to yes-no questions: a developmental 
study in English, French, and Korean. Developmental Psychology 27.3, 407-420. Cook, Vivian. J. (1991). The poverty of the stimulus argument and multicompetence. Second Language Research 7.2, 103-117.

Cook, Vivian. J. (2002). Background to the L2 use. In Vivian. J. Cook , ed., Portraits of the L2 use, 1-28. Clevedon, UK: Multilingual Matters.

Cook, Vivian. J. (2003). Introduction: The changing L1 in the L2 user's mind. In Vivian. J. Cook , ed., Effects of the Second language on the first, 1-18. Clevedon, UK: Multilingual Matters.

Cook, Vivian. J. (2008). Multi-competence: Black hole or warmhole for SLA research? In ZhaoHong Han, Andrea Revesz, Eun Sung Park, Charles Combs, and $\mathrm{Ji}$ Hyun Kim, eds., Understanding second language processing, 16-26. Clevedon: Multilingual Matters.

Doherty-Sneddon, Gwyneth, Vicki Bruce, Lesley Bonner, Sarah Longbotham, and Caroline Doyle. (2002). Development of gaze aversion as disengagement from visual information. Developmental Psychology 38, 438-445.

Han, ZhaoHong, Andrea Revesz, Eun Sung Park, Charles Combs, and Ji Hyun Kim, eds. (2008). Understanding second language processing. Tonawanda, NY: Multilingual Matters Ltd.

Hwang, Haeshin. (2004). The influence of early English education on children's bilingual development. Korean Journal of Human Ecology 13.4, 497-506.

Jarvis, Scott. (2003). Probing the effects of the L2 on the L1: A case study. In Vivian Cook, ed., Effects of the second language on the first, 81-102. Clevedon, England: Maultilingual Matters.

Jasińska, Kaja. K. and Petitto, Laura-Ann. (2017). Age of Bilingual Exposure Is Related to the Contribution of Phonological and Semantic Knowledge to Successful Reading Development. Child Development, 88.3, 1-22. March 23, 2017. doi: $10.1111 /$ cdev.12745.

Joh, Jeongsoon, Ko, HyunSook, Lim, Injae, and Lee, Shinsook. (2010). The impact of English language learning on the acquisition of native language among Korean children. The Applied Linguistics Association of Korea 26.3, 101-141.

Kang, Sang-Gu. (2011). English attrition in Korean-English bilingual children. Unpublished doctoral dissertation. University of Hawaii at Manoa, Honolulu, U.S.A.

Kecskes, Istvan. (1998). The state of L1 knowledge in foreign language learners. WORD, Journal of the International Linguistics Association 49.3, 321-340.

Kecskes, Istvan. (2010a). Dual and multilingual systems. International Journal of Multilingualism 7.2, 91-109.

Kecskes, Istvan. (2010b). Situation-bound utterance as pragmatic acts. Journal of 
Pragmatics 42, 2889-2897.

Kecskes, Istvan and Tunde Papp. (2003). How to demonstrate the conceptual effect of L2 on L1? In Vivian. Cook, ed., The effect of L2 on L1, 247-267. Clevedon: Multilingual Matters.

Kim, Byengswu and Mina Lyu. (2014, October 15). Park, Honggeun, Ilbu yengeywuchiwen ilyenkyosuppi kukliptay samnyen tunglokkum (Park, Honggeun, Student registration fee for one-year English kindergarten equal that for three-year studying at some national universities in Korea). Yonhapnews, 1.

Kim, Soon-Ham Park. (1962). The meaning of yes and no in English and Korean. Language Learning 12.1, 27-45.

Kwon, Dueon. (1991). Coki yengekyoywukuy mucecemul malhanta (Speaks on the problems of early learning of English). Hankwuknontan 24, 18-20.

Kyoyukkwahakkiswulpwu. (Ministry of Education, Science, and Technology, 2000a). Kuke ssuki (Korean writing) 2-2. Seoul: Tayhankyokwase Co.

Kyoyukkwahakkiswulpwu. (Ministry of Education, Science, and Technology, 2000b). Kuke malhaki (Korean speaking) 2-2. Seoul: Tayhankyokwase Co.

Kyoyukkwahakkiswulpwu. (Ministry of Education, Science, and Technology, 2001a). Kuke ilkki (Korean reading) 3-2. Seoul: Tayhankyokwase Co.

Kyoyukkwahakkiswulpwu. (Ministry of Education, Science, and Technology, 2001b). Kuke malhaki (Korean speaking) 3-2. Seoul: Tayhankyokwase Co.

Kyoyukkwahakkiswulpwu. (Ministry of Education, Science, and Technology, 2001c). Kuke ssuki (Korean writing) 3-2. Seoul: Tayhankyokwase Co.

Kyoyukkwahakkiswulpwu. (Ministry of Education, Science, and Technology, 2001d). Kuke tutki (Korean listening) 3-2. Seoul: Tayhankyokwase Co.

Kyoyukkwahakkiswulpwu. (Ministry of Education, Science, and Technology, 2001e). Kuke tutki (Korean listening) 2-2. Seoul: Tayhankyokwase Co.

Lee, Hwa-Ja. (2000). Chwihakcen atonguy yengekyoywukuy mokwukewa incipaltaley kkichinun yenghyang (A study on the impact of preschool English instruction on the mother tongue and cognition development). The Journal of English Language Teaching 12.1, 145-165.

Lee, Kyeongheon. (2013, September 5). Yeongywua sakyoyuk, ciyekbyel pyencha khe (Big gap in English learning by young learners through tutoring depending on cities). Tolonnywus (news for discussion), p. 4.

Li, Charles and Sandra Thompson. (1976). Subject and topic: A new typology of language. In Charles Li, ed., Subject and topic, 457-489. New York: Academic Press.

Lim, Hongbin. (2007). Hankwukeuy curuceywa tongsa pwunsek (Topic in Korean and its syntactic analysis). Seoul: Seoul National University Press. 
Lim, Jung Hyun. (2015). Translation asymmetry in Korean middle school students learning English. Language Research 51.2, 361-381.

Liu, Yingqin and William Carney. (2012). Multi-competence at the discourse level: A comparison of persuasive essays by Chinese college and high school EFL students. Journal of Language Teaching and Research 3.6, 1061-1070.

Pavlenko, Aneta and Scott Jarvis. (2002). Bidirectional transfer, Applied Linguistics 23.2, 190-214.

Pavlenko, Aneta and Barbara Malt. (2011). Kitchen Russian: cross-linguistic differences and first-language object naming by Russian-English bilinguals. Bilingualism: Language and Cognition 14.1, 19-45.

Schjerve, Rosita. R. and Eva Vetter. (2012). European Multilingualism: current perspectives and challenges. Toronto, Canada: Multilingual Matters.

Schmid, Monika. and Elise Dusseldorp. (2010). Quantitative analysis in a multivariate study of language attrition: the impact of extralinguistic factors. Second Language Research 26, 125-160.

Schoofs, Petra. (2013). The mutual influence of the first and second languages in German and English L1 speakers in second language environments. Unpublished doctoral dissertation, Newcastle University, Newcastle Upon Tyne, UK.

Selinker, Larry. (1972). Interlanguage, IRAL (International Review of Applied Linguistics) 10, 209-231.

Selinker, Larry. (1992). Rediscovering interlanguage, London: Longman.

Statistics Korea. (2014). 2013nyen sakyoywukpi cosa kyelkwa (2013 Report on Private Education Expenses). Seoul: Statistics Korea.

Tablebi, Seyed H. (2013). Cross-linguistic transfer (from L1 to L2, L2 to L1, and L2 and L3) of reading strategies in a multicompetent mind. Journal of Language Teaching and Research 4.2, 432-436.

Ventureyra, Valerie. and Christophe Pallier. (2004). The case of adopted Koreans in France. In Monika Schmid, Barbara Köpke, Merel Keijzer, and Lina Weilemar, eds., First Language Attrition: interdisciplinary perspectives on methodological issues, 207-221. Amsterdam: John Benjamins. 
HyunSook Ko

Dept. of English Language and Literature, 14-514, The University of Ulsan

Daehak-ro 93, Nam-gu, Ulsan, Korea 44610

E-mail: hyunsko@ulsan.ac.kr

Received: February 20, 2017

Revised version received: March 23, 2017

Accepted: March 26, 2017 


\section{APPENDIX}

Sample of Completion Test with Answering Negative Questions [ESL version 15$)$ ]

[1-15] Read the sentences below and press either the key, 1 for ung or the key, 0 ani(ya) for the blanks to complete the answer.

(e.g.) 오빠: 힘들지?

Oppa: Himdul-ci?

(Elder Brother: Are you tired?)

동생: , 괜창아.

Dongsaeng: , kwaynchanh-a.

(Younger Sister: , I'm okay.) [meaning I am not tired.]

1. 언니: 밥 먹었니?

Enni: Pap an mek-ess-ni?

(Elder Sister: Didn't you have a meal?)

동생: , 안 먹었어.

Dongsaeng: an mek-ess-e.

(Younger Brother: I didn't) [meaning I didn't have a meal.]

15) Romanization (following Yale) and blanks are added for readers; they were not provided in the test. 